\title{
ANTARCTIC METEOROLOGY
}

A SYMPOSIUM on "Antarctic Meteorology" was held in Melbourne during February 18-25. It was attended by meteorologists from eleven countries. About half the participants had been in the Antarctic during the preceding year, and this gave the discussion an added interest and a feeling of immediacy. The preparatory work carried out at the Commonwealth Bureau of Meteorology, and the smooth organization under the chairmanship of W. J. Gibbs, as well as the friendly hospitality, contributed to the success of the meeting.

The following topies were discussed in seven successive sessions, each with its own session chairman: (1) local effects (K. Langlo); (2) synoptic analysis and forecasting (J. Van Mieghem); (3) synoptic influences on lower latitudes (J. F. Gabites) ; (4) circulation studies (W. J. Gibbs); (5) snow and ice characteristics (G. de Q. Robin); (6) heat and mass exchanges (C. H. B. Priestly) ; (7) elimatological aspects (J. J. Taljaard).

In practice, certain themes went through the whole symposium and were discussed repeatedly in different sessions from different points of view. One of these was the katabatic wind, which is one of the most spectacular features of antaretic meteorology. Descriptions of local katabatic winds at Mawson, Wilkes, and over the ice cap were given by P. J. R. Shaw, J. Zimmerman and K. B. Mather. The abrupt onset of katabatic winds at D'Urville and other coastal places may be accompanied by an advancing wall of drifting snow ; this so-called Loewe's phenomenon was described by B. Valtat. B. L. Dzerdzeevski discussed the effect of the local topography and of the general synoptic situation upon the genesis of the katabatic winds and G. M. Tauber showed that their intensity depends on cyclonic activity over the oceans near the coast. Tauber also discussed the annual and diurnal variation of these winds in coastal regions and suggested that the diurnal variations must cause the turbulent vertical transport of heat to have a maximum during night time. R. H. Clarke described model studies carried out with the aid of a cold dome in a rotating dish pan. One of the most interesting papers on katabatic winds was presented by F. K. Ball. It gave the theory of airflow under an inversion along a rough, inclined surface. The theory indicates that katabatic stream lines should form an angle of about $40^{\circ}$ with the fall line. Along the coast, this causes relatively strong winds at the eastern side of a headland or on the western shores of a bay. It also causes particularly strong katabatic winds in the south-west quadrant of off-shore depressions. These theoretical predictions are in good agreement with observations and with 'Tauber's investigations.

Another subject which came up repeatedly in different sessions was the intense heating which occurs in the antarctic stratosphere in spring. The antarctic stratosphere at $20 \mathrm{~km}$. cools gradually by about $60^{\circ} \mathrm{C}$. from February to September. With the return of the Sun the stratosphere warms up again; a large part of the warming (65 per cent) is accomplished within a few weeks towards the end of October or early November. K. Hanson presented a case-study of this explosive stratospheric warming over the
Antarctic in October 1958. Conditions in 1957 were described by E. Flowers. Comparing arctic and antarctic conditions, $\mathrm{H}$. Wexler (whose paper was presented in his absence by M. J. Rubin) directed attention to the fact that the heating in the Arctic is slightly less pronounced and that it occurs before the return of the Sun in February. In the Antaretic it occurs well after the return of the Sun. Wexler explained the spectacular warming of the polar stratosphere by a change in the circulation patterns which leads to large-scale subsidence. This view is not easily reconciled with investigations into advection across the antarctic boundary by M. J. Rubin, whose studies showed no evidence of systematic divergence from the Antarctic in the troposphere and lower stratosphere during summer. Rubin, however, did not study specifically the period in which the stratospheric heating occurs. E. B. Kraus showed that the heating cannot be due to direct absorption of solar radiation. He suggested that it may be caused by advection of moist warm air in the troposphere which results in a change in the long wave-lengths radiation balance above. This view would be in agreement with Hanson's case-study, which indicates a warming of the lower polar troposphere a few days before the rapid stratosphere heating occurred.

As regards equipment, much interest centred on automatic weather recording systems. American automatically reporting weather stations which did not require manual erection and could be dropped from the air were described by W. S. Lanterman. An automatic non-recording elimatological station which had been left by the Japanese expedition at Syowa Bay during winter 1958 was discussed by Y. Morita and N. Murakoshi. Traps to measure the lateral transport of snow by drifting were tested by M. Mellor at Mawson. From an analysis of these drift measurements it was deduced by Mellor and U. Radok that the lateral transport of snow was even larger than had been anticipated hitherto. To gain maximum height for upper air measurements a special balloon valve had been developed at the University of Melbourne. V. D. Hopper stated that balloons equipped with this valve reached generally a height of $35 \mathrm{~km}$. with a maximum of $43.5 \mathrm{~km}$. The result of ozone observations at Halley Bay were described by J. MacDowall.

$J$. F. Gabites gave a lucid account of the antarctic heat balance. He found the flow of heat across $55^{\circ} \mathrm{S}$. to be of the same order or only a little higher than the flow across $55^{\circ} \mathrm{N}$. in spite of the greater meridional temperature difference. This could be explained by the smaller effect of friction over the ocean-covered southern hemisphere, which allows the establishment of greater vertical wind gradients and therefore greater horizontal temperature and density gradients.

Circulation in the upper air was the subject of a paper by W. B. Moreland and was also discussed in several other contributions. A stratospheric jet is a well-marked feature of the winter circulation. As in the Arctic, this polar night jet appears to be synoptically separated from the systems of the troposphere. There are, however, significant differences between the two polar regions. In the Arctic the jet core is commonly found at the $25 \cdot \mathrm{mb}$. level ; in the 
south it occurs at a lower elevation. The jet stream persists there also later into the polar day, as may be expected from the later heating of the antarctic stratosphere. It has not been possible so far to investigate synoptically the effect of the final collapse in spring of the polar night jet upon the circulation pattern in lower latitudes.

The scarcity of observations from the Southern Ocean area inevitably affected general circulation studies and the discussion of the interaction between the Antarctic and lower latitudes. In presenting his paper on antaretic synoptic analyses, W. J. Gibbs suggested that the presence and the main features of cyclones and anticyclones can be diagnosed by the analyst though there was still considerable doubt about the reality of frontal analyses. Synoptic studies of cold outbreaks and surges had been prepared by a number of Australian authors (A. K. Hannay, R. Falconer and H. M. Treloar, F. A. Berson and U. Radok). Circulation studies based on synoptic material were presented by J. Langford, I. S. Kerr, H. van Loon and S. Karelski.
Synoptic conditions over the antarctic ice cap itself are now reasonably well known for the first time. The communication system required to achieve this end was described by T. I. Gray, jun. It appears that cyclones do occasionally penetrate deep into the Antaretic and that fronts move sometimes right across the South Pole, though this occurs not as often as is probably the case in the north. In general, high-latitude cyclones seem to move sluggishly along the coast.

The happy international co-operation established between meteorologists in the Antarctic is perhaps symbolized by a paper submitted by P. D. Astapenko (U.S.S.R.) which was based on a joint investigation by him, J. Alt (France) and M. Ropar (United States). It is hoped that this co-operation will be continued in the International Antarctic Analysis Centre which is now being set up under the ægis of the Australian Bureau of Meteorology at Melbourne and that the work carried out there will lead to a better understand. ing of meteorological problems as a whole.

E. B. Kraus

\section{HYDROGEN LIQUEFACTION}

$\mathrm{T}$ HE use of liquid hydrogen, first produced and collected by Dewar at the Royal Institution in 1898, has, until recently, been largely confined to the laboratory. With a normal boiling point of $20.4^{\circ} \mathrm{K}$. it provides a convenient means of controlling the temperature for experiments in the range $14^{\circ}-90^{\circ} \mathrm{K}$. and it is used as a precooling agent in the liquefaction of helium.

On March 12, a one-day symposium on "Hydrogen Liquefaction and Associated Techniques", organized by the Low Temperature Group of the Physical Society, was held at the Institute of Physics in London, and it was ovident from the attendance at the meeting, as well as the topies discussed, that interest in the liquefaction of hydrogen on an industrial scale is developing in Great Britain.

The morning session, under the chairmanship of Dr. P. H. Sykes, was opened by Prof. G. O. Jones (Queen Mary College, London), who spoke of the applications of liquid hydrogen in pure research. He pointed out that it is necessary to go well below temperatures obtainable with liquid hydrogen in order to study the interesting features of many phenomena. Nevertheless, liquid hydrogen is of great technical assistance in many experiments. In optical spectroscopy, for example, the reduction in thermal motion of atoms at low temperatures results in a decreased Doppler broadening of spectral lines. The use of liquid hydrogen in bubble chambers, where it may form both a target and a detector for nuclear reactions, has also proved of great value.

In certain experiments, however, there is little point in working at temperatures below $20^{\circ} \mathrm{K}$. For example, the thermal expansion coefficients of most substances and variations in such properties of the solidified inert gases as the density, compressibility and refractive index become so small below $20^{\circ} \mathrm{K}$. that they are difficult to measure with precision. Such experiments may very conveniently be performed in miniature hydrogen liquefiers with about $100 \mathrm{ml}$. of liquid and in which liquefaction commences some 15 min. after starting at room temperature.

The design and construction of small-scale liquefiers were discussed by Dr. D. H. Parkinson (Radar
Research Establishment, Malvern), who emphasized the ease with which liquid hydrogen may be produced in the laboratory with relatively simple and inexpensive apparatus. High-pressure hydrogen, usually from a cylinder, is precooled with liquid nitrogen and then expanded at a valve into a reservoir. A proportion of the gas liquefies and the remainder is used to cool the incoming high-pressure gas by means of a heat exchanger between the liquid hydrogen and nitrogen stages. The yield of liquid depends rather critically on the pressure and precooling temperature ; for example, a standard $120 \mathrm{cu}$. ft. capacity cylinder exhausted from 120 to 50 atmospheres would yield 0.36 litre of liquid if the gas were precooled to $77^{\circ} \mathrm{K}$. and 0.55 litre with a precooling temperature of $65^{\circ} \mathrm{K}$. Impurities, usually amounting to about 0.1 per cent in commercial hydrogen, must be removed from the gas or they will solidify and block the liquefier tubes, and $150 \mathrm{gm}$. of activated charcoal cooled in liquid nitrogen was recommended as an adequate absorber for each cylinder of gas.

The use of liquid hydrogen as a source of 'cold' has already been mentioned, and an application to the production of a beam of low-energy neutrons was described by Dr. F. J. Webb (Atomic Energy Research Establishment, Harwell). Neutrons from a reactor with, say, a heavy-water moderator at a temperature of $50^{\circ} \mathrm{C}$. are thermal neutrons, that is, slow neutrons with energies of the same order as the thermal energies of atoms in a solid. They are spread over a range of values with the greatest number possessing energies corresponding to a de Broglie wave-length of about 1 A. In certain diffraction experiments, however, it is necessary to employ neutrons with wave-lengths greater than $4 \mathrm{~A}$., the number of which is relatively small compared with those of $1 \mathrm{~A}$. wavelength. Since the thermal energy is proportional to the absolute temperature, the kinetic energies of the neutrons may be reduced, and their wave-lengths correspondingly inereased, by using liquid hydrogen as a moderator. In the Dido reactor at Harwell, a small hydrogen liquefier feeds a 3-in. diameter container placed in the neutron beam and the liquid hydrogen moderator results in a gain of the order of 